Running Head: USING RAPID REVIEW METHODS

\title{
Using Rapid Review Methods for Topics in Religion
}

Paul Fehrmann

Maria Hawkins

\begin{abstract}
Author Notes
Paul Fehrmann is an Associate Professor, and Reference, Instruction and Collection Development Librarian with responsibilities for Religion and Philosophy at the University Libraries, Kent State University, Kent, Ohio
\end{abstract}

Maria Hawkins is a Library Specialist at the University of Akron, Akron Ohio

Correspondence concerning this article or research should be addressed to Paul Fehrmann University Libraries, Kent State University, Kent, OH 44242. Contact: pfehrman@kent.edu 


\begin{abstract}
In academia the traditional literature review (TLR) is used to provide a summary look at what has been 'done before'. However, critics poiint to the potential for biased representation of topics when TLR are used. A large systematic review methods (SR) literature offers evidence that the shortcomings of TLR might be minimized. Moreover, SR methods themselves are evolving; "rapid reviews" and "scoping" are a new approaches for picturing the literature on topics. We report on our use of these methods to map the social science literature on the broad topic of "intolerance in religion", and we discuss our experience to date with the rapid review and scoping methodologies. The literature of SR methods does seem a valuable resource for guidance that can serve librarians and researchers as they work on reviews addressing topics in religion.
\end{abstract}




\section{Using Rapid Review Methods for Topics in Religion}

In all academic disciplines it is common to see authors refer to what is found in the literature; and in many areas the traditional literature review is used to provide a summary look at what has been done before. However, among other concerns, critics have pointed to the potential for biased representation of topics when traditional approaches to reviews (hereafter referred to as "reviews" or "review") are used. Some have pointed to the possibilities for unconscious or conscious "cherry picking" of publications to support a reviewers viewpoint or for using an unrepresentative subset of literature (e.g., Strech \& Sofaer, 2012), or to the lack of details about the steps taken or key decisions made as reviews are developed (Golder, Loke, \& McIntosh, 2008; Liberati et al., 2009). In response, a large systematic review (SR) methods literature in the health and social sciences offers itself as evidence that the shortcomings of reviews might be significantly reduced. Additionally, SR methods are themselves developing, and two approaches which have been explored and adapted for a range of topics are the "rapid review" and "scoping".

Prior work suggested that the use of SR methods is rare for topics in religion (Fehrmann \& Wagner, 2012), and the current report is a continuation of what seems to be a worthwhile exploration of such methods for addressing issues in religion. Our paper reports on our use of methods from the rapid review and scoping literature to map the social science literature on the topic of intolerance and religion.

Following this introduction, the paper has six additional sections. In the first section, as background, we briefly sketch information on traditional literature reviews, and systematic 
reviews, as well as describing rapid review and scoping methodology. The second section presents our use of rapid review and scoping methods to map the social science literature on the topic of intolerance and religion. A third section shows results. Our fourth section provides a discussion of results, and a fifth section discusses next steps and brief recommendations. We close with a summary.

\section{Background}

\section{Literature reviews}

Just above we noted that reviews are common in many disciplines. Researchers can use review activities, that is, searching the literature on a topic, just to see what is known, etc. Researchers also frequently pursue reviews to set the stage or build a rationale and support for other research goals. Whatever the purposes, reviews are completed by looking for information sources on a topic; and those sources can found in one's own library, in institutional libraries, by contacting experts, by searching databases or the Internet, etc. This set of activities is commonly called doing a literature review, and as such it is used for products like theses, dissertations, research articles, etc. The methods used to complete reviews are learned over the years by students, and researchers. In addition, there are books that provide guidance (Fink, 2010; Jesson, Matheson, \& Lacey, 2011; Machi \& McEvoy, 2012).

\section{Systematic reviews}

A systematic review (SR) is a type of literature review. SR have been developed in large part to mitigate the possibility that reviews will have the negative characteristics noted earlier (i.e., cherry picking resources, unrepresentative sets of resources, etc.), and the literature on SR methods is large. Major organizations have manuals and guidelines for completing SR: the Cochrane Collaboration (www.cochrane.org); the Campbell Collaboration 
(www.campbellcollaboration.org); the EPPI-Centre (eppi.ioe.ac.uk/cms); the Janna Briggs Institute (joannabriggs.org); and the Centre for Reviews and Dissemination (www.york.ac.uk/inst/crd). There are also books (Booth, Papaioannou, \& Sutton, 2012; Cooper, 2010; Gough, Oliver, \& Thomas, 2012; Petticrew \& Roberts, 2006; Saini \& Shlonsky, 2012), as well as specialized journals (Systematic Reviews; Research Synthesis Methods).

This statement, from section 1.2.2 What is a systematic review? in the online Cochrane Handbook for Systematic Reviews of Interventions, (Green, et al., 2011), shows what is common in guidelines for SR:

A systematic review attempts to collate all empirical evidence that fits pre-specified eligibility criteria in order to answer a specific research question. It uses explicit, systematic methods that are selected with a view to minimizing bias. The key characteristics of a systematic review are:

- A clearly stated set of objectives with pre-defined eligibility criteria for studies;

- An explicit, reproducible methodology;

- A systematic search that attempts to identify all studies that would meet the eligibility criteria;

- An assessment of the validity of the findings of the included studies, for example through the assessment of risk of bias; and

- A systematic presentation, and synthesis, of the characteristics and findings of the included studies.

The timeframe for SR is listed as 6 months to 2 years (Khangura, Konnyu, Cushman, Grimshaw, \& Moher, 2012), and SR are commonly completed by teams of researchers. Looking 
at this SR statement and list of characteristics, it does seem that parallel approaches might be used for review projects that address topics in religion.

Also, though, the methods for SR are evolving. Two SR approaches recently gaining use are scoping (to map literatures) and the rapid review. The goals and steps for these are described next.

\section{Rapid reviews}

Rapid reviews are a type of SR (Ganann, Ciliska, \& Thomas, 2010; Khangura et al., 2012). The Centre for Research and Dissemination (CRD) has been involved in SR for many years, and they give the following brief description of rapid reviews:

Rapid reviews offer a quick overview of a specific topic and can be extremely useful to give an insight into issues, policy and/or practice in a particular subject area. Literature is located through limited searching and can be based on research literature, policy or practice evidence. Rapid reviews can be invaluable if you are not familiar with an area and need to commission a very quick piece of research to give you some background. Although a rapid review will not give you a definitive, exhaustive review of the evidence base, nor will it exclude all bias, it will gather and review evidence in a streamlined systematic way in the time available and produce an overview report outlining key points in a format which is easy to understand and digest." (Centre for Information and Reviews, n.d.).

Although the methods are still new, the steps below can be viewed as typical of the rapid review process depicted in the literature (Khangura et al., 2012). The listing can be compared to that for SR noted above.

- Needs assessment 
- Question development and refinement

- Proposal development and approval

- Systematic literature search

- Screening and selection of studies

- Narrative synthesis of included studies (including assignment of evidence level)

- Report production

- Ongoing follow-up and dialogue with knowledge users

While the steps above do correspond to those seen the normal SR process, all rapid reviews will seek to use an abbreviated but effective and useful systematic process. The timeframe for rapid reviews, in contrast to SR described above, is stated as 5 weeks or less (Khangura et al., 2012); and such reviews may be completed by one or a few researchers.

\section{Scoping}

Scoping is also a type of SR. Scoping studies seek to map the concepts, main sources, and types of evidence available for a given research topic (Arksey \& O'malley, 2005), and are characterized as a kind of initial reconnaissance review (Davis, Drey, \& Gould, 2009) that can be more iterative than full SR. Scoping is also described by the CRD:

A scoping study also gives a quick overview of a particular area but is used to map or demonstrate how much evidence is available. As scoping studies identify the range of literature available on a certain subject, they can be used to make the case for a rapid evidence assessment or full systematic literature review. Scoping studies provide a map of the literature without synthesising the evidence within each item.

Correspondingly, Anderson et al. (2008) offer this: 
The most common form of scoping study is a map of the relevant literature. These vary in scope from general accounts of the literature to studies that are just short of systematic reviews....In almost all areas the literature is vast, diffuse and of variable quality. Literature mapping aims to provide an initial indication of the location of the literature relating to a particular issue and to identify its overall size. Its objective is to map out the literature as it stands, without any immediate plan to review it systematically.

Recent papers using and critiquing the use of scoping list and describe the following steps (Levac, Colquhoun, \& O'Brien, 2010; Rumrill, Fitzgerald, \& Merchant, 2010). Again, the steps can be compared to SR and rapid review guidance.

- Identify the initial research questions

- Identify the relevant studies

- Study selection

- Charting

- Collating, summarizing, and report the results

- Optional consultation stage

\section{Our Use of Rapid Review And Scoping Methods}

Drawing from the current work providing guidance on rapid review and scoping methods, we looked to address our topic of religion and intolerance as covered in the social sciences.

\section{Research question}

How is the topic of "intolerance and religion" addressed in the social science literature?

\section{Definitions}


Social science literature. We defined social science literature as the publication output found in these disciplines: Anthropology, History, Political Science, Psychology, and Sociology. Along with other approaches noted below, two broad disciplines we did not include at this time are Education and Business.

Intolerance. At this stage in our research we defined the concept of intolerance as whatever the authors of research articles took it to mean. As is common, as literature search results are examined, more precise concepts can be iteratively defined to guide subsequent research steps. Also, as will be seen below, for our project we did assume that authors presenting research on tolerance would need to be considered as well. Papers studying the latter could vey well be focused on intolerance.

Religion. Similar to our definition for the concept of intolerance, our concept of religion was defined as whatever the authors were discussing when they used the term religion. Again, the next steps of research would likely develop and work with a more targeted definition.

\section{Literature search resources and search strategies}

Common expectations and recommendations in SR are for the following search methods to be used and then described so readers can see how searches were pursued; for example see this list in the Cochrane Handbook, section 6.6.2.2 Reporting the search process in the review (Green, et al., 2011).

- List all databases searched.

- List grey literature sources.

- List individuals or organizations contacted.

- List any journals and conference proceedings specifically handsearched for the review.

- List any other sources searched (e.g. reference lists, the internet). 
At this stage in our project we only used the commercial databases that we list below. Such computer searches are a core part of full SR studies, and were viewed as sufficient for our current purpose. All database names and description quotes below are from the EBSCOhost website listing of databases (EBSCO, n.d.). Hereafter the term EBSCO is used interchangeably with the term EBSCOhost.

ATLA Religion Database. "This database contains over 1.75 million bibliographic records covering the research literature of religion in over 60 languages. Most coverage spans from 1908 to the present, while an ambitious retrospective indexing project provides citations of select titles back to their original publication date. Bibliographic records represent scholarship on major religions, faiths, denominations and languages."

Anthropology Plus. "A compilation of the Anthropological Index Online and Anthropological Literature databases, this resource is an extensive index of bibliographic materials covering the fields of anthropology, archaeology, and related interdisciplinary research."

America: History and Life. "This bibliographic resource provides a robust source of information focusing on the history and life of the United States and Canada. Selective indexing includes over a thousand journals dating back over 55 years. This source has proved to be an important bibliographic reference tool for students and scholars of U.S. and Canadian history."

Historical Abstracts "This exceptional resource covers the history of the world (excluding the United States and Canada), focusing on the 15th century forward Historical Abstracts is essential for libraries supporting upper-division and graduate research. History and social science researchers have used this database to discover significant and groundbreaking work for more than 50 years." 
International Political Science Abstracts "This database is the authoritative global standard in support of scholarly research in political science and proximate disciplines. This resource tool provides abstracts of virtually all the relevant articles published in journals (and yearbooks) around the world, helping researchers and students efficiently locate and exploit the latest in the professional literature."

PsycINFO "This database is the APA's renowned resource for abstracts of scholarly journal articles, book chapters, books and dissertations. PsycINFO is the largest resource devoted to peer-reviewed literature in behavioral science and mental health, with ninety-nine percent of the covered material peer-reviewed...PsycINFO provides unmatched coverage of behavioral science and mental health fields, containing over 3.5 million citations and summaries dating as far back as the 1600s, with one of the highest DOI matching rates in the publishing industry. Journal coverage, which spans from 1800 s to present, includes international material selected from around 2,500 periodicals in dozens of languages."

Political Science Complete "This database provides extensive coverage of global political topics with a worldwide focus, reflecting the globalization of contemporary political discourse. Designed specifically for students, researchers and government institutions, Political Science Complete (PSC) contains full text for hundreds of journals along with indexing and abstracting for thousands of publications...provides over 340 full-text reference books and monographs and over 38,000 full-text conference papers...comparative politics, humanitarian issues, international relations, law and legislation, non-governmental organizations and political theory."

SocINDEX This database provides "...comprehensive coverage of sociology, encompassing all sub-disciplines and closely related areas of study. These include abortion, 
criminology and criminal justice, demography, ethnic and racial studies, gender studies, marriage and family, political sociology, religion, rural and urban sociology, social development, social psychology, social structure, social work, socio-cultural anthropology, sociological history, sociological research, sociological theory, substance abuse and other addictions, violence and many others."

Our computer search strategies looked to see the treatment of our topic over the last 20 years: 1994-1998; 1999-2003; 2004-2008; 2009-2014. We also searched 2013-2014. As indicated above, we used 7 major databases and searches to discover where and how intolerance in religion was being covered in the social sciences: that is, in the five disciplines of anthropology, history, political science, psychology, and sociology. As will be discussed below, comparable searches were used in ATLA. All searches were run on May 13, 2014. The searches we used for each of these areas are shown below as copied and pasted from the EBSCO search history screen. That kind of reporting of searches is recommended for SR, as it supports evaluation and possible reproducibility of searches.

\section{Anthropology}

Database - Anthropology Plus

Interface - EBSCOhost Research Databases

Search Screen - Advanced Search

Search modes - Boolean/Phrase

Query (default field) ( toleran* or intoleran*) AND relig*

Limiters - Year of Publication: 2013-2014; Publication Type: article; Language: english

\section{History}

Two Databases - America: History \& Life; Historical Abstracts 
Interface - EBSCOhost Research Databases

Search Screen - Advanced Search

Search modes - Boolean/Phrase

Query (default field) ( toleran* or intoleran*) AND relig*

Limiters - Published Date: 20130101-20141231; Publication Type: Academic Journal;

Document Type: Article; Language: English

\section{Political Science}

Two Databases - International Political Science Abstracts; Political Science Complete

Interface - EBSCOhost Research Databases

Search Screen - Advanced Search

Search modes - Boolean/Phrase

Query (default field) ( toleran* or intoleran*) AND relig*

Limiters - Published Date: 20130101-20141231; English Language; Publication Type: Academic

Journal; Document Type: Article

\section{Psychology}

Database - PsycINFO

Interface - EBSCOhost Research Databases

Search Screen - Advanced Search

Search modes - Boolean/Phrase

Query (default field) ( toleran* or intoleran*) AND relig*

Limiters - Published Date: 20130101-20141231; Publication Type: Peer Reviewed Journal;

English; Document Type: Journal Article

\section{Sociology}


Database - SocINDEX with Full Text

Interface - EBSCOhost Research Databases

Search Screen - Advanced Search

Search modes - Boolean/Phrase

Query (default field) ( toleran* or intoleran*) AND relig*

Limiters - Scholarly Journals; Date of Publication: 20130101-20141231; Document Type:

Article; Language: English

For these searches, the search terms (see Query above) were searched in the EBSCO default field search, and, as an example, this is what the EBSCO information says about that search in the Searchable Fields section of the online database help for PsycINFO: "The default fields for unqualified searches consist of the following: Title, Translated Title, Classification Codes, Abstract, Keyword, Subjects, and Author.” (EBSCO PsycINFO Database, n.d.)

The publication date limit information for each search listed indicates a publication time for 2013-2014. The publication timeframe information was different, of course, for each of these four 5-year periods we searched: 1994-1998; 1999-2003; 2004-2008; 2009-2014.

Along with the 5 general searches listed above using religion (relig*) as a term to discover articles on religion, we used the following searches as additional approaches to find research addressing intolerance and any of 5 specific major religions.

- Christianity: christian* AND (toleran* or intoleran*)

- Buddhism: buddhis* AND (toleran* or intoleran*)

- Islam: (muslim* or islam*) AND (toleran* or intoleran*)

- Hinduism: hindu* AND (toleran* or intoleran*)

- Judaism: (jew* or judai*) AND (toleran* or intoleran*) 
Those 5 searches were run on all 7 social science databases combined, again as free text default field searches, and for the timeframes previously noted.

In order to see comparable search results in the religion literature, we used two searches in the ATLA Religion database.

We first used the following search to match what we used in the other 7 discipline databases: (toleran* or intoleran*) AND relig* Limiters - Scholarly (Peer Reviewed) Journals; Year Published: 2013-2014; Language: English

A second search used the following: DE "toleration, religious" and Limiters - Scholarly (Peer Reviewed) Journals; Year Published: 2013-2014; Publication Type: Article; Language: English.

The searches above were used as a basis for a paper presented on June 5, 2014 at the 2014 Annual Conference on Information \& Religion, Center for the Study of Information and Religion, Kent State University, Kent, Ohio. As we note below, those broad searches, that we show results for in Table 1. were updated on October 17-18, 2014; results for the latter are also presented in Table 1.

Before presenting and discussing our search results, we note the following select list of EBSCO databases. It shows other resources that could be considered for the kind of broad social science mapping project we are working on. The bold resources are what we used.

\section{- American History \& Life}

\section{- Anthropology Plus}

- Business Source Complete

- Central \& Eastern European Academic Source

- EconLit 
- Education Research Complete

- Gender Studies Database

- Historical Abstracts

- International Political Science Abstracts

- Index to Jewish Periodicals

- Jewish Studies Source

- Legal Collection

- Middle Eastern \& Central Asian Studies

- Peace Research Abstracts

- Political Science Complete

- PsycINFO

- Public Affairs Index

- SocINDEX

\section{Results}

Table 1 shows results of our searches with 8 EBSCO databases completed on May 13, 2014. The left column indicates the social science disciplines we looked at and the databases used. The next seven columns give the number of articles for different timeframes for each of the 5 disciplines. Also, as noted earlier, for comparison, we searched ATLA. For ATLA the top numbers in each cell are results for searches that used the search term combination used for the social science databases. That is, (toleran* or intoleran*) AND relig*. The second search used this controlled vocabulary (or descriptor) search in EBSCO: DE "Toleration, Religious". It is often recommended in the SR literature that computer searches should use controlled vocabulary, thesaurus terms, or descriptors; those techniques can find relevant material that common, default 
free text searching does not discover. The last column shows results for updated searches for the ATLA and the five social science areas. The updated searches were run on October 17-18, 2014. During the update it was noticed that EBSCO automatically eliminated what it called "exact duplicates". This occurred in the Political Science and History searches; both of those searches used two databases. The duplicates may have arisen from an overlap between the databases for those searches; those unanalyzed duplicate results might account for the lower number of hits shown in column 8 of Table 1. relative to the number for those areas in column 7 . In addition to showing results in Table 1., the following URL can be used to connect to a "working bibliography" for a set of 2615 items that represents the combination of the updated search results for the 5 social science areas shown in the last column. A link to this bibliography is also located on a web site that is being used for managing and sharing information, and potentially collaborating on projects, related to the use of SR methods for topics in philosophy and religion (libguides.library.kent.edu/srpr).

\section{Table 1.}

Number of articles addressing "intolerance and religion”

\begin{tabular}{|c|c|c|c|c|c|c|c|}
\hline $\begin{array}{c}\text { Discipline and } \\
\text { EBSCO } \\
\text { Database }^{\text {a. }}\end{array}$ & $\begin{array}{c}1994- \\
1998\end{array}$ & $\begin{array}{c}1999- \\
2003\end{array}$ & $\begin{array}{r}2004- \\
2008\end{array}$ & $\begin{array}{c}2009- \\
2014\end{array}$ & $\begin{array}{r}2013- \\
2014\end{array}$ & $\begin{array}{c}20 \text { Year } \\
\text { Total }\end{array}$ & $\begin{array}{c}20 \text { Year } \\
\text { Total }^{\text {b. }}\end{array}$ \\
\hline $\begin{array}{c}\text { Religion } \\
\text { ATLA }\end{array}$ & $\begin{array}{l}23 \\
39\end{array}$ & $\begin{array}{l}21 \\
30\end{array}$ & $\begin{array}{l}21 \\
76\end{array}$ & $\begin{array}{l}32 \\
78\end{array}$ & $\begin{array}{l}4 \\
9\end{array}$ & $\begin{array}{c}97 \\
223\end{array}$ & $\begin{array}{l}126 \\
235\end{array}$ \\
\hline $\begin{array}{c}\text { Anthropology } \\
\text { Anthropology } \\
\text { Plus }\end{array}$ & 0 & 3 & 8 & 4 & 0 & 15 & 15 \\
\hline $\begin{array}{c}\text { History } \\
\text { Historical } \\
\text { Abstracts; } \\
\text { American History } \\
\text { \& Life }\end{array}$ & 180 & 215 & 261 & 188 & 44 & 844 & 807 \\
\hline
\end{tabular}




\begin{tabular}{|c|c|c|c|c|c|c|c|}
\hline $\begin{array}{c}\text { Political Science } \\
\text { International } \\
\text { Political Science } \\
\text { Abstracts; } \\
\begin{array}{c}\text { Political Science } \\
\text { Complete }\end{array}\end{array}$ & 71 & 152 & 397 & 480 & 102 & 1100 & 1096 \\
\hline $\begin{array}{c}\text { Psychology } \\
\text { PsycINFO }\end{array}$ & 34 & 50 & 76 & 116 & 34 & 276 & 292 \\
\hline $\begin{array}{c}\text { Sociology } \\
\text { SocINDEX }\end{array}$ & 63 & 64 & 122 & 163 & 44 & 412 & 405 \\
\hline
\end{tabular}

Notes:

a. The second to seventh columns show number of results from searches on May 13, 2014.

b. The eighth column shows results from searches on October 17-18, 2014.

Table 2 shows results for a second way of thinking about where research is being done on intolerance and religion. The focus here is on search results for what can be seen as significantly different religions. The left column shows the default keyword searching that we used for each of the 5 world religions. The right column shows the number of results for the 2013-2014 timeframe.

Table 2.

Number of articles on "intolerance" and "specific religions"

\begin{tabular}{|c|c|}
\hline Religion and Search Terms & $\begin{array}{c}\text { Number of Search Results } \\
\text { 2013-2014 }\end{array}$ \\
\hline Christianity \\
christian* AND (toleran* or intoleran*)
\end{tabular}




\begin{tabular}{|c|c|}
\hline $\begin{array}{c}\text { Hinduism } \\
\text { hindu* AND (toleran* or intoleran*) }\end{array}$ & 9 \\
\hline Buddhism & 3 \\
buddhis* AND (toleran* or intoleran*) & \\
\hline
\end{tabular}

\section{Discussion of Results}

Given the initial searching we completed, we did begin to see broad outlines of how intolerance and religion are being covered by the social sciences. First, the results suggest that most academic research was published in the disciplines of history and political science for each of the five year periods examined and for the 20 year period from 1994 to 2014, with sociology and psychology following in numbers of research articles, and with anthropology showing much less research on the topic.

Also, looking at the initial numbers, it seems that quite a bit more was published on our topic for the religions of Christianity and Islam than for the other religions listed. Importantly, though, the current search was limited to English publications.

After looking at broad numbers for the disciplines and/or for major religions, what seems a fairly straightforward way to begin to identify topics being studied is to look at the titles of articles. As a very rapid technique, though potentially with unclear results, looking at titles of articles can suggest the specific topics being addressed. As an example, our Appendix A lists the bibliographic information for the 34 results (Table 1.) obtained from our first search in psychology for 2013-2014. Also, while it is a compilation that needs refining, the titles of the "working bibliography" we described earlier might be perused for indications of topics being addressed in the academic social science literature.

In addition to the data that we show and discuss above, given our focus on using 
guidance from the SR literature, with special attention to rapid review and scoping methodology, we share the following. The work to date has been accomplished over a month, during the spring semester at an academic setting, while the authors were involved in their normal library responsibilities. That "normal" included 60 hours of "research time" the first author was given during that month, with hours arranged around other scheduled activities. With respect to software, the "hits" for the searches have been saved to our RefWorks database; similar database tools include EndNote (endnote.com), Mendeley (www.mendeley.com), and Zotero (www.zotero.org). We anticipate that a next possible step in RefWorks, as frequently indicated in SR methods, would involve removing duplicates (i.e., identical items discovered in different database, etc.). Above we also shared some results from our initial look at titles; that sample list (Appendix A) was created using RefWorks. The "working bibliography" was also created in RefWorks.

\section{Next Steps and Recommendations}

For this paper we worked with a broad topic that we expect might serve as a foundation for other more targeted projects; and we are proceeding with the overall project. By continuing on our project, with respect to method, we will become more acquainted with SR approaches to literature reviewing. Substantively, we expect to contribute to addressing one or more targeted questions pertaining to intolerance and religion.

Again, we described and provided pointers to resources that provide a framework for learning about and then pursuing reviews on topics in religion that use methods from the systematic review literature. Specific approaches that might be explored and used are those called rapid reviews and/or scoping. Next, because we detailed the searches we used to date, along with ourselves, readers might also reproduce what we have done, and then add to the 
search strategies to move to more comprehensive scanning for relevant literature. The extensions to what we have done would involve added search terms, and more search resources, etc. The details we reported for our searching are also, in small measure, an example of the kind of reporting expected in SR that can lead to or provide the basis for confidence in the conclusions reached.

We anticipate that a next possible step in RefWorks, as frequently indicated in SR methods, would involve removing duplicates (i.e., identical items discovered in different databases, etc.). For example, we expect that this process might be pursued with the working bibliography. Above we also shared some results from our initial look at titles; that sample list (Appendix A) was created using RefWorks. Following the sequence of steps for SR (including rapid review or scoping) RefWorks could also be used collaboratively to examine abstracts; two researchers are recommended for increasing reliability of choices at the "abstract" level. We would proceed with the following set of actions. Using what are called "inclusion/exclusion" criteria that we determine, looking at abstracts we would identify studies relevant to the targeted question, then select desired full text of studies to retrieve and retrieve select full articles. Next we would chart desired information from those studies to address specific questions, and collate that information. Next we would synthesize or summarize, and finally report the results. Importantly, readers should note that there is SR literature that explains that decisions during all of these steps can be iteratively be modified. For example, examining abstracts can lead to additional computer search strategies. Reviewing full text may also lead to additional searches. Both abstracts and full text can lead to modified charting decisions, and so on. Key to such actions is the detailed documenting of decisions, an expectation that has been emphasized routinely in the SR literature as they seek to promote the transparency that in turn supports 
confidence in results.

Our reading and our experience with rapid review and scoping methods so far does seem to show that such methods can be used for topics in religion. As librarians we could pursue a range of studies using such methods. We could also serve on teams of researchers, collaborating with those trained in religion. We would recommend and hope that librarians will work to see how SR methods can be used to provide these kinds of activities and services.

\section{Summary}

Systematic review (SR) methods are urged as approaches that can enhance the rigor of literature reviews. For example, strategies have been developed to reduce the possibilities for unconscious or conscious "cherry picking" of publications to support a reviewer's viewpoint, or the possibilities for their using an unrepresentative subset of literature in their reviews. Our goal in pursuing the current project has been to explore the use of SR methods for topics in religion, and to develop and present an initial framework and package that others might use. As librarians we examined current SR literature to learn of methods; and we chose to use guidance from the literature on rapid review and scoping methods. We outlined those methods; and we noted relevant SR resources for further learning. We also presented results for the rapid review and scoping steps that we have used (to date) to address the following broad research question: how is the topic of "intolerance and religion" addressed in the social science literature? We provided access to a current working bibliography, and we also indicated what a number of next steps might be. The literature of SR methods does seem a valuable resource for guidance that can serve librarians and researchers as they work on reviews addressing topics in religion. 


\section{References}

Anderson, S., Allen, P., Peckham, S., \& Goodwin, N. (2008). Asking the right questions:

Scoping studies in the commissioning of research on the organisation and delivery of health services. Health Research Policy and Systems, 6(1), 1-12. doi:10.1186/1478-4505-6-7

Arksey, H., \& O'malley, L. (2005). Scoping studies: Towards a methodological framework. International Journal of Social Research Methodology, 8(1), 19-32.

Booth, A., Papaioannou, D., \& Sutton, A. (2012). Systematic approaches to a successful literature review. London: Sage.

Centre for Information and Reviews. (n.d.). Retrieved from http://www.nfer.ac.uk/research/centre-for-information-and-reviews/

Cooper, H. M. (2010). Research synthesis and meta-analysis : A step-by-step approach. Los Angeles: Sage.

Davis, K., Drey, N., \& Gould, D. (2009). What are scoping studies? A review of the nursing literature. International Journal of Nursing Studies, 46(10), 1386-1400.

EBSCO PsycINFO Database (n.d.) Retrieved from http://support.ebsco.com/help/index.php?help_id=DB:803

EBSOChost (n.d.) Retrieved from http://www.ebscohost.com/academic/ 
Fehrmann, P. \& Wagner, S. (2012) A Systematic Literature Review Model for Religion. Advances in the Study of Information and Religion. Available at: http://digitalcommons.kent.edu/asir/vol2/iss1/4

Fink, A. (2010). Conducting research literature reviews :From the internet to paper (3rd ed.). Los Angeles: Sage.

Ganann, R., Ciliska, D., \& Thomas, H. (2010). Expediting systematic reviews: Methods and implications of rapid reviews. Implementation Science, 5(1), 56. doi:10.1186/1748-5908-556

Golder, S., Loke, Y., \& McIntosh, H. M. (2008). Poor reporting and inadequate searches were apparent in systematic reviews of adverse effects. Journal of Clinical Epidemiology, 61(5), 440-448. doi: 10.1016/j.jclinepi.2007.06.005

Gough, D., Oliver, S., \& Thomas, J. (2012). An introduction to systematic reviews. London: Sage.

Green, S., Higgins, J., Alderson, P., Clark, M., Mulrow, C., \& Oxman, A. (2011). Chapter 1: Introduction. In Cochrane Handbook for Systematic Reviews of Interventions (Version 5.1.0 (updated March 2011). The Cochrane Collaboration. Retrieved from www.cochranehandbook.org

Jesson, J., Matheson, L., \& Lacey, F. M. (2011). Doing your literature review :Traditional and systematic techniques. Los Angeles, Calif. ; London: Sage. 
Khangura, S., Konnyu, K., Cushman, R., Grimshaw, J., \& Moher, D. (2012). Evidence summaries: The evolution of a rapid review approach. Systematic Reviews, 1(1) doi:10.1186/2046-4053-1-10

Levac, D., Colquhoun, H., \& O'Brien, K. K. (2010). Scoping studies: Advancing the methodology. Implementation Science, 5(1), 1-9.

Liberati, A., Altman, D. G., Tetzlaff, J., Mulrow, C., Gotzsche, P. C., Ioannidis, J. P., Clarke, M., Devereaux, P. J., Kleijnen, J., \& Moher, D. (2009). The PRISMA statement for reporting systematic reviews and meta-analyses of studies that evaluate health care interventions: Explanation and elaboration. PLoS Med, 6(7), e1000100.

Machi, L. A., \& McEvoy, B. T. (2012). The literature review :Six steps to success (2nd ed.). Thousand Oaks, Calif.: Corwin Press.

Petticrew, M., \& Roberts, H. (2006). Systematic reviews in the social sciences :A practical guide. Malden, MA; Oxford: Blackwell Pub.

Rumrill, P. D., Fitzgerald, S. M., \& Merchant, W. R. (2010). Using scoping literature reviews as a means of understanding and interpreting existing literature. Work: A Journal of Prevention, Assessment and Rehabilitation, 35(3), 399-404. doi:10.3233/WOR-2010-0998

Saini, M., \& Shlonsky, A. (2012). Systematic synthesis of qualitative research. New York, NY: Oxford University Press.

Strech, D., \& Sofaer, N. (2012). How to write a systematic review of reasons. Journal of Medical Ethics, 38(2), 121-126. doi:10.1136/medethics-2011-100096 


\section{Appendix A. Psychology articles on topic of "intolerance and religion"}

Al Sadi, F. H., \& Basit, T. N. (2013). Religious tolerance in Oman: Addressing religious prejudice through educational intervention. British Educational Research Journal, 39(3), 447-472.

Alvi, A. (2013). Concealment and revealment: The muslim veil in context. Current Anthropology, 54(2), 177-191.

Awwad, J., Nassar, A., Usta, I., Shaya, M., Younes, Z., \& Ghazeeri, G. (2013). Attitudes of Lebanese university students towards surgical hymen reconstruction. Archives of Sexual Behavior, 42(8), 1627-1635.

Baines, N. (2013). Epilogue: The moderation of rhetoric. The Sociological Review, 61(Suppl 2), 196-208.

Bangwayo-Skeete, P. F., \& Zikhali, P. (2013). Explaining self-declared social tolerance for human diversity in Latin America and the Caribbean. Forum for Social Economics, 42(2-3), 181-206.

Barringer, M. N., Gay, D. A., \& Lynxwiler, J. P. (2013). Gender, religiosity, spirituality, and attitudes toward homosexuality. Sociological Spectrum, 33(3), 240-257.

Brandt, M. J., \& Reyna, C. (2014). To love or hate thy neighbor: The role of authoritarianism and traditionalism in explaining the link between fundamentalism and racial prejudice. Political Psychology, 35(2), 207-223. 
Cao, L., \& Maguire, E. R. (2013). A test of the temperance hypothesis: Class, religiosity, and tolerance of prostitution. Social Problems, 60(2), 188-205.

Crosby, J. W., \& Varela, J. G. (2014). Preferences for religious help-seeking: Racial and gender differences, interfaith intolerance, and defensive theology. Mental Health, Religion \& Culture, 17(2), 196-209.

de Figueiredo, J. M. (2013). Prevention of demoralization in prolonged bicultural conflict and interaction: The role of cultural receptors I-Description of a natural experiment. The International Journal of Social Psychiatry, 59(5), 419-430.

DeMaris, A. (2013). Burning the candle at both ends: Extramarital sex as a precursor of marital disruption. Journal of Family Issues, 34(11), 1474-1499.

Dimitrova, R., Chasiotis, A., Bender, M., \& van de Vijver, F. (2013). Collective identity and wellbeing of Roma minority adolescents in Bulgaria. International Journal of Psychology, 48(4), 502-513.

Dunkel, C. S., \& Hillard, E. E. (2014). Blasphemy or art: What art should be censored and who wants to censor it? The Journal of Psychology: Interdisciplinary and Applied, 148(1), 1-21.

Farris, M. (2013). Tolerance and liberty: Answering the academic left's challenge to homeschooling freedom. Peabody Journal of Education, 88(3), 393-406.

Hart, J. W., Sullivan-Sanchez, C., Packer, T., \& Loveless, J. (2013). Is any explanation better than no explanation? intolerance of uncertainty and paranormal beliefs. Social Behavior and Personality, 41(2), 343-344. 
Heiphetz, L., Spelke, E. S., Harris, P. L., \& Banaji, M. R. (2013). The development of reasoning about beliefs: Fact, preference, and ideology. Journal of Experimental Social Psychology, 49(3), 559-565.

Hill, M. J. (2013). Is the black community more homophobic?: Reflections on the intersectionality of race, class, gender, culture and religiosity of the perception of homophobia in the black community. Journal of Gay \& Lesbian Mental Health, 17(2), 208214.

Hirschman, E. C. (2013). Back to the future: Islamic Spain as a model for marketing efflorescence. Marketing Theory, 13(4), 513-520.

Holland, L., Matthews, T. L., \& Schott, M. R. (2013). “That's so gay!” exploring college students' attitudes toward the LGBT population. Journal of Homosexuality, 60(4), 575-595.

Jones, J., \& Shanks, A. (2013). Laid bare: Religious intolerance within online commentary about 'bare below the elbows' guidance in professional journals. Health Care Analysis, 21(3), 271-281.

Osman-Gani, A. M., Hashim, J., \& Ismail, Y. (2013). Establishing linkages between religiosity and spirituality on employee performance. Employee Relations, 35(4), 360-376.

Paglieri, F., Borghi, A. M., Colzato, L. S., Hommel, B., \& Scorolli, C. (2013). Heaven can wait. how religion modulates temporal discounting. Psychological Research, 77(6), 738-747.

Patrick, K., Heywood, W., Simpson, J. M., Pitts, M. K., Richters, J., Shelley, J. M., \& Smith, A. M. (2013). Demographic predictors of consistency and change in heterosexuals' attitudes 
toward homosexual behavior over a two-year period. Journal of Sex Research, 50(6), 611619.

Perry, S. L. (2013). Multiracial church attendance and support for same $\square$ sex romantic and family relationships. Sociological Inquiry, 83(2), 259-285.

Rashad, H. (2014). Health equity in the Arab world: The future we want. The Lancet, 383(9914), 286-287.

Ruah $\square$ Midbar, M., \& Klin $\square$ Oron, A. (2013). 'Tell me who your enemies are': Government reports about the 'cult' phenomenon in israel. Journal for the Scientific Study of Religion, 52(4), 810-826.

Sagioglou, C., \& Forstmann, M. (2013). Activating christian religious concepts increases intolerance of ambiguity and judgment certainty. Journal of Experimental Social Psychology, 49(5), 933-939.

Schlösser, O., Frese, M., Heintze, A., Al-Najjar, M., Arciszewski, T., Besevegis, E., Zhang, K. (2013). Humane orientation as a new cultural dimension of the GLOBE project: A validation study of the GLOBE scale and out-group humane orientation in 25 countries. Journal of Cross-Cultural Psychology, 44(4), 535-551.

Sheard, M. K., Ross, S. M., \& Cheung, A. (2013). Social-emotional learning championing freedom, education and development: A vehicle for at-risk students to succeed. Cypriot Journal of Educational Sciences, 8(1), 1-18. 
Shen, M. J., Haggard, M. C., Strassburger, D. C., \& Rowatt, W. C. (2013). Testing the love thy neighbor hypothesis: Religiosity's association with positive attitudes toward ethnic/racial and value-violating out-groups.Psychology of Religion and Spirituality, 5(4), 294-303.

Smeekes, A., \& Verkuyten, M. (2014). When national culture is disrupted: Cultural continuity and resistance to Muslim immigrants. Group Processes \& Intergroup Relations, 17(1), 4566.

Snow, R. C., Winter, R. A., \& Harlow, S. D. (2013). Gender attitudes and fertility aspirations among young men in five high fertility east african countries. Studies in Family Planning, 44(1), 1-24.

Van Tongeren, D. R., McIntosh, D. N., Raad, J. M., \& Pae, J. (2013). The existential function of intrinsic religiousness: Moderation of effects of priming religion on intercultural tolerance and afterlife anxiety. Journal for the Scientific Study of Religion, 52(3), 508-523.

Wu, Y., Yang, Y., \& Chiu, C. (2014). Responses to religious norm defection: The case of Hui Chinese Muslims not following the halal diet. International Journal of Intercultural Relations, 39, 1-8. 
